\title{
Effects of High Frequency Mechanical Impact on Fatigue Life of Semi-Automated Gas Metal Arc Welding (GTAW) of HSLA Butt Weld
}

\author{
Salina Saidin ${ }^{1,2}$, Dahia Andud ${ }^{2,3}$, Yupiter H. P. Manurung ${ }^{2}$, Muhd. Faiz Mat ${ }^{2}$, Noridzwan Nordin ${ }^{2}$ and Martin Leitner ${ }^{4}$ \\ ${ }^{1}$ Nusantara Technologies Sdn, Bhd., Selangor, Malaysia \\ ${ }^{2}$ Faculty of Mechanical Engineering, Universiti Teknologi MARA (UiTM) Shah Alam, Selangor, Malaysia. \\ ${ }^{3}$ Universiti Kuala Lumpur Malaysia France Institute, Selangor, Malaysia. \\ ${ }^{4}$ Chair of Mechanical Engineering, Montanuniversität Leoben, Austria.
}

\begin{abstract}
This paper deals with a comprehensive investigation of fatigue life enhancement on semiautomated Gas Metal Arc Welding (GTAW) butt weld joint which is found almost everywhere in Malaysia welding structure steel sectors. The selected material in this study was high strength low alloy steel S460G2+M commonly used extremely in steel structure due to its outstanding mechanical properties. In this investigation, the method for joining the butt weld was conducted by unprofessional welder using semi-automated GMAW. At first, suitable welding parameters were identified and formulated into welding procedure specification (WPS) qualification conforming to AWS D1.1 standard. The test specimens were prepared and tested to ensure the welding quality. Further, the HFMI using Pneumatic Impact Treatment (PIT) technique were applied at the weld toe of the butt weld as tool for fatigue life enhancement. To investigate the influence of HFMI/PIT on the fatigue strength, the specimens were undergone fatigue test using universal fatigue machine using a constant amplitude loading. Finally, the comparison of the fatigue strength of as welded and treated specimens to indicate the beneficial influence of the treatment. Yes, the conduction by unprofessional welder using semi-automatic GMAW, the findings showed the improvement of fatigue strength and slope of S-N curves. In addition, the fracture location of test specimen shows physically affected by shifting from critical weld transition to base metal. The tensile test and hardness value also showed a slight difference as compared to untreated specimens.
\end{abstract}

\section{Introduction}

Fatigue failure is a worldwide issue on the heavy industry structure, especially on the offshore, building and bridge construction. The main problem with the fatigue phenomena is that it can happen below the yield strength of the material properties whilst exposed to the cyclic load. However the international standards such as IIW, ASTM and ISO standard have been established the FAT class for fatigue structure design calculation references. Susceptibility to fatigue depends on three fundamental factors which [1] are : repeated loads, number of loading cycles and stress concentration. To reduce the possibility of fatigue failure happen to the structure or parts, the selection of the suitability material and joining method are significant and counted with application purpose.

High strength low alloy (HSLA) steels were developed to create a variety of the low-carbon steels for the wide range industries include oil and gas, automotive, bridges construction, offshore and heavy industries in order to improve the strength-to-weight ratio and meet the need for higher-strength construction grade materials [2]. HSLA steels demonstrate a specific desirable mechanical properties compared with conventional carbon steels, such as high strength, excellent ductility, and good weldability, and also exhibit outstanding low temperature impact toughness superior to that of high yield strength steels [3].

The steel grade used for this study is $\mathrm{S} 460 \mathrm{G} 2+\mathrm{M}$ stated as high strength low alloy steel particular in the European Standard (EN10225) which is designed for an offshore structure which applied in harsh environments such as wave and sea water [4]. The technical delivery condition state $+\mathrm{M}$ are shown that thermomechanical control rolling process (TMCP) has been carried out on final deformation in certain temperature ranges to achieve a fine grain material condition. The TMCP process enhanced the mechanical properties by the addition of small amounts of alloys and special processing techniques such as controlled rolling and accelerated cooling methods [3]. These processes produce a fine grain structures and enhanced the strength value for the steel. The TMCP steel not only offers the

Corresponding author: muhdfaiz7062@salam.uitm.edu.my 
best safety and reliability, the steel also provides the basis for an excellent fabrication efficiency due to their good weldability and formability [5]. Thus, these steels can be engaged for highly efficient welding procedures necessary for the serious production of offshore structure.

GMAW welding process can be operated in semi-automatic and automatic. In this study, the semiautomated process has been implemented which is essentially a consequence of manual welding, where the filler electrode is replaced with a continuous, automatically fed welding wire. The GMAW method used a wire feeding gun that can feeds wire at an adjustable speed and flows an argon-based shielding gas or a mix of Argon (Ar) and carbon dioxide $\left(\mathrm{CO}_{2}\right)$ over the weld puddle to protect it from atmospheric contamination. The advantages of GMAW include its wire feeding capability which allows long weld beads to be deposited, widely used in robotic arc welding process, can be used in all positions and typically less welder skill is required.

The subject to be concerned on this study is the sustainability of the HSLA welded joint to the dynamic load stress. The welding process on the HSLA material may formed a tensile residual stress and the welded joints are most susceptible to the fatigue induced crack due to sharp geometric profile at the weld toe. However, there is a lot of methods to enhance the fatigue strength on welded steel structure. These methods can be divided into two categories. The first method is weld geometry improvement such as burr grinding and TIG dressing. The second category is residual stress modification which is separated by mechanical and thermal treatment [6].

In this fatigue life study, High frequency mechanical impact (HFMI) treatment has been used to complement both categories to improve fatigue strength. HFMI is a modern technique to support steel structural industries by improving the fatigue strength of welded structures with modifying the residual stress state using either ultrasonic or pneumatic technologies. HFMI makes use of cylindrical indenters which are accelerated against a component with high frequency. This method is known by many names: ultrasonic impact treatment (UIT), ultrasonic peening (UP), ultrasonic peening treatment (UPT), high frequency impact treatment (HiFiT), pneumatic impact treatment (PIT) and ultrasonic needle peening (UNP) [7].

Pneumatic Impact Treatment (PIT) is a new innovation of a high frequency mechanical impact treatment (HFMI) with the aim to improved fatigue life on dynamic loaded structure. HFMI/PIT also worked as anti-aging method which helps to enhance the life time for steel structure to reduce costs by preventing and delayed the failure, repairs and loss of productions. HFMI/PIT is using higher frequency peening method to improve the fatigue strength with particular vibrated pins that changed the tensile stress to compressive stresses on the treated surface of the structure. The improvement of the fatigue strength in local critical areas, especially weld toe could increase significantly the efficiency of fatigue behavior on the welded steel structure. The impacted material is highly plastically deformed causing changes in the material microstructure and the local geometry as well as the residual stress state in the region of impact. [8].

The numerous studies on the HFMI/PIT post weld mechanical treatment of welded joints of HSLA have been developed past decade and still an arise new technologies to cater the fatigue issue on the welded design structural to enhance the lifetime application. Refer to the Leitner studied [9], the fatigue life of the HFMI/PIT treated specimen is nearly the fatigue strength of the untreated base material value. The effect of HFMI/PIT on the butt joint, transverse T-joint and longitudinal welds attachment on 5mm HSLA S690 shows the FAT-class increased by a factor of 1.2 for butt joint, 1.6 for transverse T-joint and 2.5 for longitudinal weld attachment as compared to the as-welded condition. The fatigue crack initiation also shifted from end of weld seam to the heat-affected zone area of the base material after HFMI/PIT treatment. These paper also evaluated the effectiveness of notch stress approach on the welded joint and found that the butt joint has lower stress concentration factor which made it higher endurance strength as compared to the T-joint and the longitudinal attachment. They also investigated the effect of HFMI/PIT on the fatigue life of mild construction steel S355 up to ultra high-strength steel S960. They found that the S355 steel reaches for all three specimen types about $85 \%$ of the base material fatigue stress range and also for the high strength steel S690 are almost equal to the base material fatigue strength behavior. In the highcycle fatigue region, the post-treatment shows a significant enhancement compared to the finite lifetime regime. The base material stress range can be reached for the high- strength steel joints with HFMI treatment. All fatigue test data points are above the IIW recommendation, even if a bonus factor of 1.5 for HFMI treatment and a benign thinness bonus factor are applied [10]. Leitner et al.[11] found that the influence and effective of stress ratio may be related to the fundamental change in the local residual stress state. HFMI-treated high-strength steel joints it is observed that the effect of the HFMI-induced compressive residual stress state acts as significant benefit factor to increase the fatigue resistance due to this post-treatment technique and leads to a reduction of the local residual stress condition.

HFMI/PIT have many advantages over the traditional hammer peening. Its produce more consistent result for the treatment of the weld joints. The fluidic muscle system employed in the HFMI/PIT allows the device to apply a consistent peening force onto the working surface and creates a more consistent weld toe notch. This system also produces much lower vibrations than regular air hammer, as low as $5 \mathrm{~ms}^{-2}$, which would allow the operator to work continuously for up to 8 hours. The actuator of the hammering gun operates at a 
low voltage of $24 \mathrm{~V}$ which allows it to be safely operated underwater.

\section{Welding Quality Assurance}

To ensure the welded structure is sustained, secured and long run to be used, the good quality welding procedure specification shall be produced to meet all the standard requirements such by controlling and monitor a welding parameter. A good weld quality shall influence the fatigue strength behaviour. The identification of welding parameters are basically begin with extensive trial of current and voltage of the welding machine for prewelding procedure specification (pre-WPS) and finally undergone welding parameter qualification to develop the actual welding procedure specification (WPS) accompanied with the welding procedure qualification record (WPQR) of the material being welded, which are fabricated in accordance to code and standard requirements practice of welding such as AWS D1.1 or ASME IX. The weldability of steel varies from other steel and each steel grade requires different welding parameter such as filler material, heat input and speed.

In this investigation, the $10 \mathrm{~mm}$ HSLA S460G2+M plate has been welded by Gas Metal Arc Welding (GMAW) process with position flat welding (1G). The filler wire used is ER80S-N1 and mixed shielding gas, which $80 \% \mathrm{Ar}$ and $20 \% \mathrm{CO}_{2}$. The welding parameter selection and welding specification qualification (WPS) for this study are according to the AWS D1.1 specification. To choose a suitable filler material for welding process, it depends on the base material mechanical property specification such as tensile strength, yield strength and chemical composition. Before the welding process, the parameters such as root face, root gap and set up is crucial for inspection in order to capture the best quality of weldment otherwise it will affect the bending test, tensile strength, yield strength and hardness results. The ultimate tensile strength is the maximum amount of tensile stress that it can achieve before breaking when exposed the static loading. While yield strength or yield point is a not sharply defined point which the stress of the material begins to plastically deform and the specimen can endure without maintained the condition permanently. Yield point defines material properties point which specimen deform elastically and returned to its original condition when the stress applied is transferred. The yield strength is the mainly important property that the designer requires to use or identify, especially to determine the $\mathrm{SN}$ analysis for fatigue design on cyclic load application and vibration.

\section{Experimental Set-up and Procedure}

\subsection{Test Specimens}

The material used was S460G2+M thermomechanical rolled structure steel with delivering plate thickness of $10 \mathrm{~mm}$ and nominal minimum yield strength of $460 \mathrm{MPa}$. The mechanical properties and chemical contents of the S460G2+M steel indicate as shown in Table 1 and 2.

Table 1. Mechanical properties of S460G2+M [4]

\begin{tabular}{|l|c|}
\hline \multicolumn{1}{|c|}{ Properties } & S460G2+M \\
\hline Yield Stress (YS), MPa & $460(\mathrm{~min})$ \\
\hline Ultimate Tensile Strength (UTS) & $540-700 \mathrm{Mpa}$ \\
\hline Elongation, Lo & $17 \%$ \\
\hline YS/UTS (MPa) & $0.93 \mathrm{Mpa}$ \\
\hline V-Notch Charpy Impact (Joule) & $60 \mathrm{~J}$ at $-40^{\circ} \mathrm{C}$ \\
\hline Carbon Equivalent Value (CEV) & $0.43 \mathrm{Max}$ \\
\hline
\end{tabular}

Table 2. Chemical Composition of S460G2+M [4]

\begin{tabular}{|c|c|c|c|c|c|c|c|c|c|c|}
\hline \multicolumn{10}{|c|}{ Element (wt \%) } \\
\hline $\mathbf{C}$ & $\mathbf{S i}$ & $\mathbf{M n}$ & $\mathbf{P}$ & $\mathbf{S}$ & $\mathbf{C u}$ & $\mathbf{M o}$ & $\mathbf{N i}$ & $\mathbf{C r}$ & $\mathbf{V}$ & $\mathbf{N b}$ \\
\hline 0.14 & $\begin{array}{c}0.15- \\
0.55\end{array}$ & 1.65 & $\begin{array}{c}0.02 \\
0\end{array}$ & $\begin{array}{c}0.00 \\
7\end{array}$ & 0.30 & 0.25 & 0.70 & 0.25 & $\begin{array}{c}0.08 \\
0\end{array}$ & $\begin{array}{c}0.04 \\
0\end{array}$ \\
\hline
\end{tabular}

The HSLA butt welded plate has been prepared with the same dimension and separated two (2) type which as welded and HFMI/PIT treated. As welded specimen was prepared as normal specimens without governing any treatment. While, HFMI/PIT treated specimen was undergone Pneumatic Impact Treatment (PIT) on the critical surface weld toe area to modify the surface geometry.

The HFMI/PIT tool is operated with pneumatic air pressure of 6 bars and a peening frequency is $90 \mathrm{~Hz}$. The pin is moved along the weld with a speed of $v=20$ to $30 \mathrm{~cm} / \mathrm{min}$ to obtain a high quality of treatment at the treated surface area. The impacting particular pins pointed on the surface of the desired structure resulting in high compressive stresses with recommendation $0.2-$ $0.5 \mathrm{~mm}$ depth range. The size of pin used to imparting the surface area was depended on the angle of the weld toe and desired surface geometry to prevent any crack occur and ensure the quality of the weld not damage. In this study, the radius of the hardened pin used is $\mathrm{R}=2 \mathrm{~mm}$ with $30^{\circ}$ to $60^{\circ}$ of pin movements along the weld toe the welds. The HFMI/PIT standard operating are also complemented with the tool calibration and implemented before performed the treatment to ensure the result of the HFMI/PIT groove dimension for a specified power setting and treatment are consistence with the pre-determined limits as IIW recommendation [12]. Figure 1 shows the Pneumatic Impact Treatment (PIT) equipment used for this study.

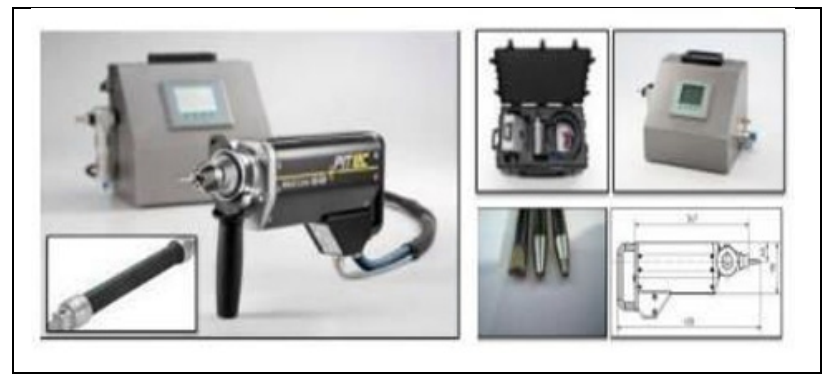

Fig. 1: HFMI/PIT treatment equipment [7] 


\subsection{Results of Tensile Test : with versus without Treatment}

In this research, the tensile tests were performed on as welded material and HFMI/PIT treated which the specimens were prepared as rectangular flat type. Tensile test specimens are a standardized cross section sample. The root and cap of the specimens have been ground flush and the dimensions referred to the AWS D1.1 standard. The size of the specimen is prepared with size $\mathrm{W}$ (width of the specimen) $=20 \mathrm{~mm}, \mathrm{~T}$ (nominal of thickness $)=10 \mathrm{~mm}, \mathrm{~L}$ (length of the specimen $)=200 \mathrm{~mm}$ and $\mathrm{Lg}$ (gauge length) $=80 \mathrm{~mm}$. Figure 2 show the schematic dimension of the tensile test specimen.

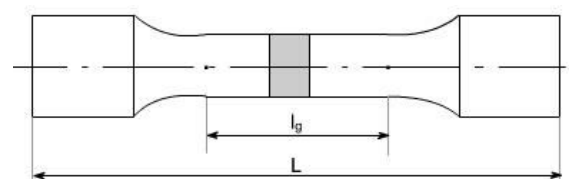

Fig. 2. Schematic dimensions of the tensile test specimen

An each two specimens tensile test have been tested for as welded and HFMI/PIT. The HFMI/PIT treated has been performed on the weld metal surface of the cap and root test specimen. All Tensile tests were performed by using 50tonne capacity load Universal Tensile Test Machine.

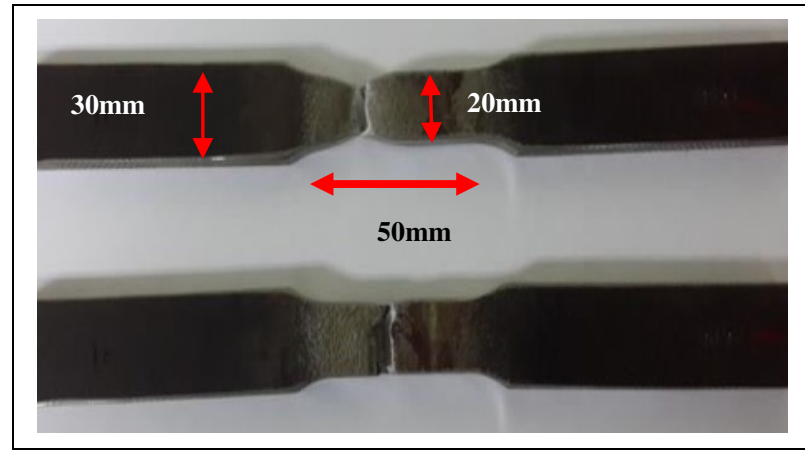

Fig. 3. HFMI/PIT tensile test specimen

The tensile test results for the overall specimens are meeting the S460G2+M requirements. The tensile test results for HFMI/PIT-treated specimen was slightly higher than as welded value. The summary of tensile strength analysis test results as shows on Table 3.

Table 3: Tensile test of S460G2+M results

\begin{tabular}{|c|c|c|c|c|}
\hline Condition & ID & $\begin{array}{c}\text { Tensile } \\
\text { Strength } \\
(\mathbf{M P a})\end{array}$ & \multirow{2}{*}{$\begin{array}{c}\text { Average } \\
(\mathbf{M P a})\end{array}$} & $\begin{array}{c}\text { Position of } \\
\text { Fracture }\end{array}$ \\
\hline \multirow{2}{*}{ As Welded } & $\mathrm{T} 1$ & 603.76 & \multirow{2}{*}{598.09} & Weld Metal \\
\cline { 2 - 3 } \cline { 5 - 5 } & $\mathrm{T} 2$ & 592.42 & & Weld Metal \\
\hline $\begin{array}{c}\text { HFMI/PIT } \\
\text { Treated }\end{array}$ & $\mathrm{T} 1$ & 630.93 & \multirow{2}{*}{631.60} & Base Metal \\
\cline { 2 - 3 } \cline { 5 - 5 } & $\mathrm{T} 2$ & 632.27 & & Base Metal \\
\hline
\end{tabular}

The visual examination has been done on all the tensile tested specimens and the fractured location for each tested specimen was recorded. The positions of fracture of the as welded specimen are broken at the weld metal while HFMI/PIT specimen broke at base metal. The figures of testing tensile test specimens have shown in figure 4 and 5 . The specimens are positively indicated a ductile surface. The results proved that the HFMI/PIT treatment also influenced the tensile strength by modified the geometry which eliminated the defects of the weld and compress the stress on the weaknesses area such as weld metal. The example of PIT specimen fractured at base metal indicated in figure 6 .

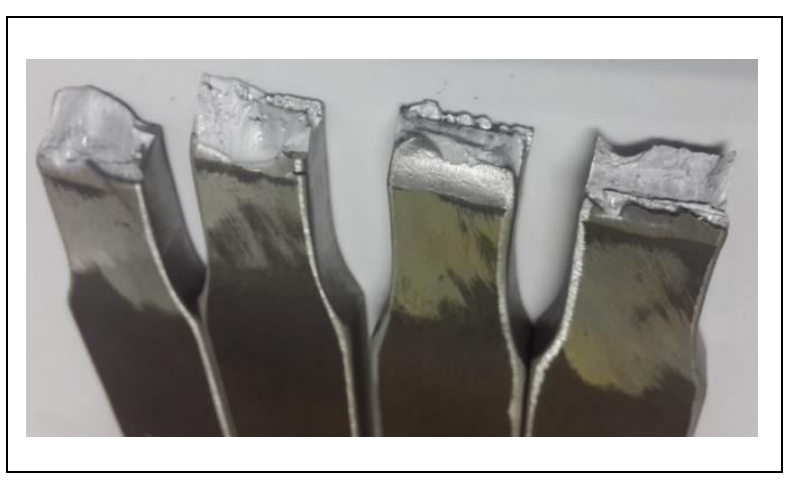

Fig. 4. Specimen as welded after tensile testing break at weld metal

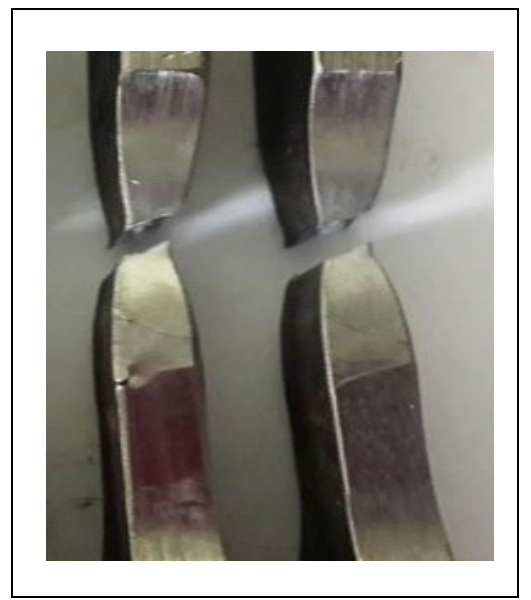

Fig.5. Specimen HFMI/PIT- treated after tensile testing

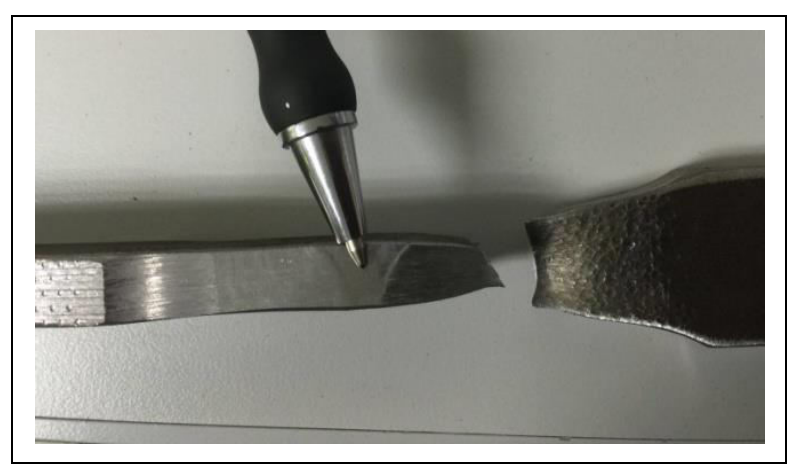

Fig. 6. Specimen HFMI/PIT-treated after tensile testing break at base metal 


\subsection{Results of Hardness Test : with versus without Treatment}

The Vickers hardness measurements were taken at the cross section of the weld specimen. Vickers microhardness was measured using a semi-auto Mitutoyo microhardnes tester, model AVK-C1, with a load of $10 \mathrm{kgf}$ (HV10). The hardness measurements performed on as welded and HFMI/PIT-treated specimens at $1.5 \mathrm{~mm}$ from cap and root area, as indicated on the hardness indentor profiles in the macrophotograph as shows in figure 7 and 8 .

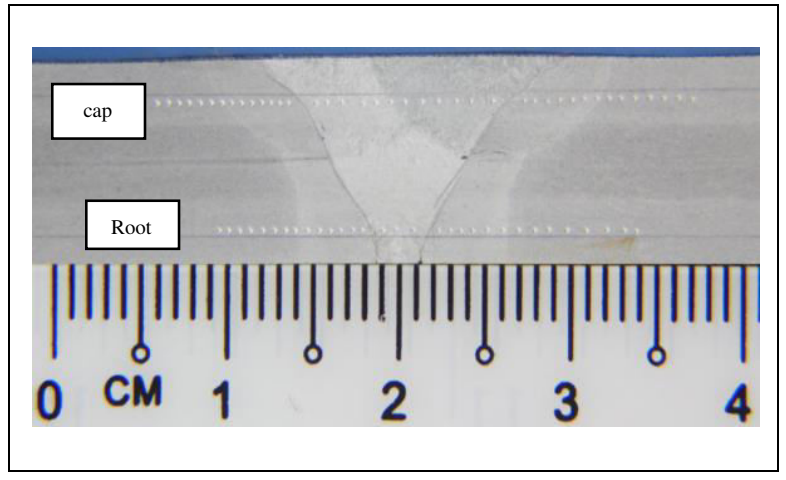

Fig. 7. Hardness indentor profile for as welded specimen

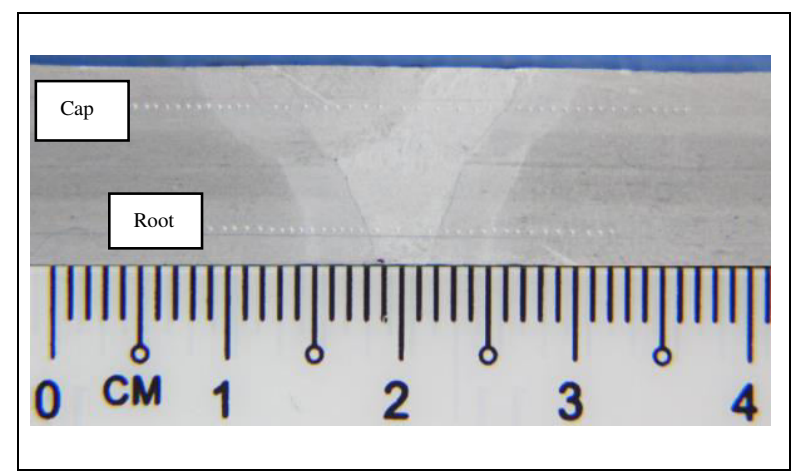

Fig. 8. Hardness indentor profile for HFMI/PIT-treated specimen

The micro-hardness analysis results were presented in chart 1 and chart 2. The hardness results showed the typical HSLA material hardness value for all location measurements. There are no specific hardness value requirements for the $\mathrm{S} 460 \mathrm{G} 2+\mathrm{M}$ material and even AWS D1.1 standard.

In order to compare the micro-hardness results, the cap and root hardness values were analyzed to verify the influenced of HFMI/PIT on the specimens. Refer to the chart below, the location cap and root for HFMI/PITtreated specimen shown an increased hardness value and more constant compared as welded specimens. The increment of hardness value apparently showed at base metal and heat affected zone (HAZ) area. The increasing of hardness value is due to the HFMI/PIT concept which modified the local geometry and deformed the plastically material by work hardening.

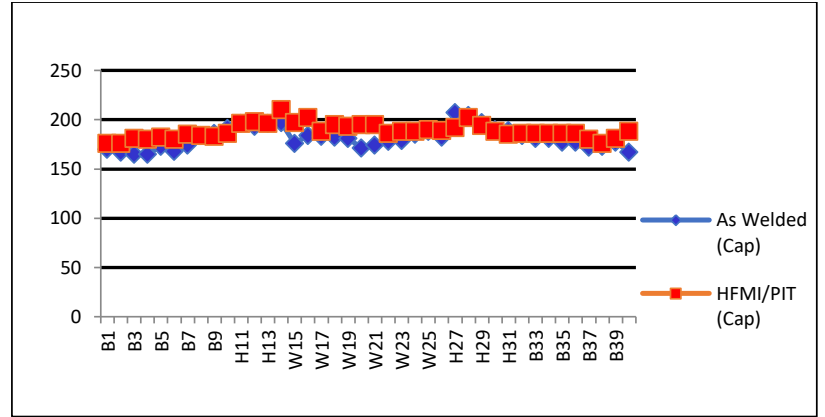

Chart 1. Hardness test value of near cap for as welded and HFMI/PIT-treated specimens

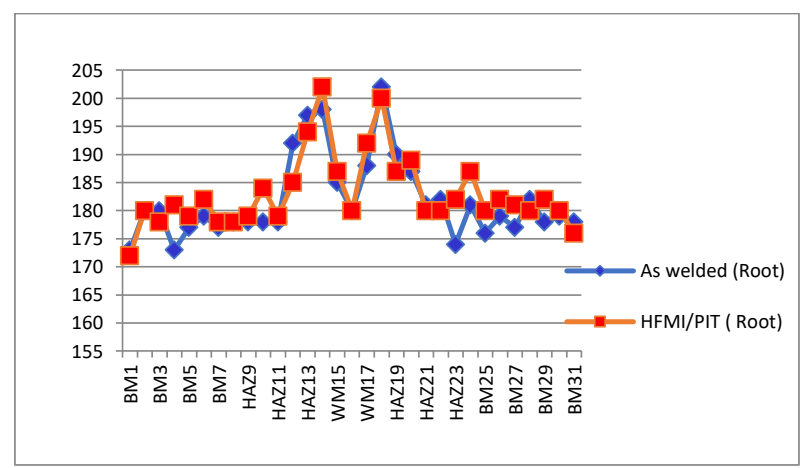

Chart 2. Hardness test value of near root for as welded and HFMI/PIT-treated specimens

\subsection{Results of Fatigue Strength Test : with vs without Treatment}

The fatigue test specimens were tested under constant amplitude loading with a stress ratio of 0.1 . A servo hydraulic INSTRON machine with a dynamic load capacity of $250 \mathrm{kN}$ was used. The testing frequency used was $5 \mathrm{~Hz}$. The fatigue size specimen prepared according to the IIW recommended which is the width, $30 \mathrm{~mm}$ and gauge length, $>60 \mathrm{~mm}$ as per Figure 6 below.

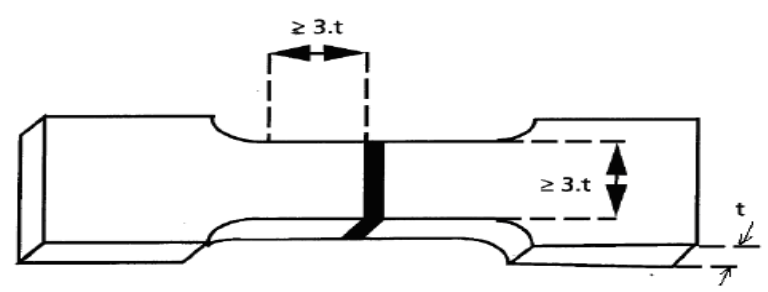

Fig. 6. Schematic dimensions of the fatigue strength test specimen [13]

The fatigue life have been analyse by using the log-normal distribution for the number of fatigues cycles of independent stress levels evaluation according to ASTM E739 [14]. The characteristic FAT class is defined by a classification of the $\mathrm{S} / \mathrm{N}$ curves based on the nominal stress ranges at $\mathrm{N}=2 \times 10^{6}$ (two million load cycles) by assuming to present a survival probability of at least $\mathrm{PS}=95 \%$. The fatigue resistance of welded joint 
is limited by the fatigue resistance of the base material [15].

The results of the fatigue life $\mathrm{S} / \mathrm{N}$-curves for HSLA S460G2+M butt weld of the as welded and HFMI/PIT treated weld specimens are shown in Figure 10. Based on the plotted S-N curve, it is appeared that both fatigue strength values of the as welded and HFMI/PIT treated specimens are showed higher improvement than the FAT value references in the IIW recommendation. The characteristics FAT value for as welded is slightly higher $21 \%$ than as welded in IIW Fatigue Design Recommendation. While, experimental results for HFMI/PIT specimens shows $30 \%$ improvement compared with IIW recommendations for HFMI post weld treatment.

Therefore, for understandable comparison purposes, S/N Curve analysis for as welded and HFMI/PIT treated condition in Figure 10 showed the bonus factor 1.3 of fatigue strength, which considers the HFMI/PIT particularly influence on the fatigue strength and fatigue life enhancement. Thereby the highest fatigue strength is obtained by using the high-strength steel S460G2+M as base material. The welded structures are much lower than those of un- welded components [16].

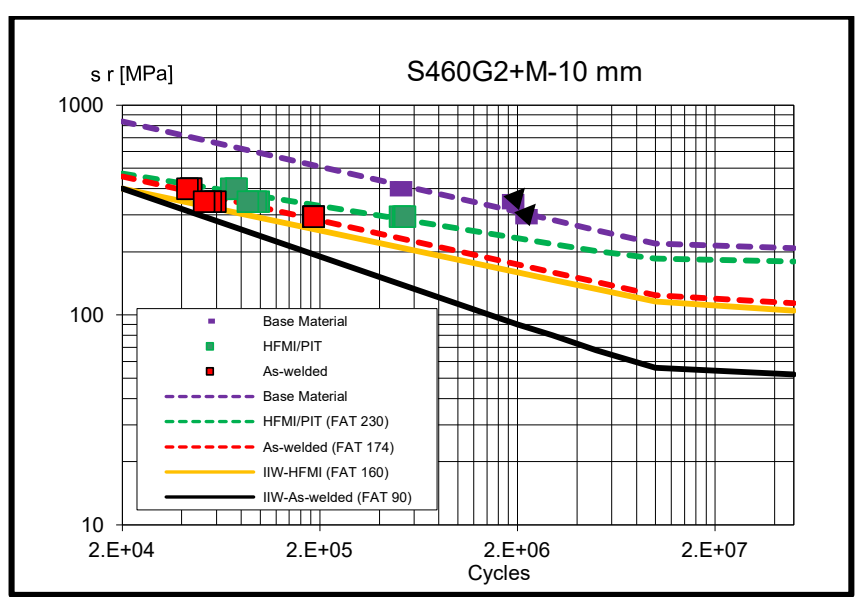

Fig. 10. Fatigue data for improved manual HSLA butt weld

\subsection{Results of Fracture Surfaces : with vs without Treatment}

The visual examination and comparison of the fracture surface of the as welded and HFMI/PIT butt joint specimens were done. The patterned of the fatigue initiation and the rupture part areas were analysed accordingly. All specimens were tested at the same load level, which are $75 \%, 65 \%$ and $55 \%$ of the yield strength of the base metal. The final fracture surface of all specimens are given in Figure 11. There were two typical zones fracture, which is fatigue fracture zone (A) and the fast rupture zone (B). As appeared on the fracture parts area for all specimens, a crack initiation (ratchet mark) appears along the weld toe line for the as welded compared to HFMI/PIT treated. Ratchet marks can result from either high stress on the part or from high stress concentration [17]. The crack initiation is appeared starting at the base metal especially on the HFMI/PIT specimen with $75 \%$ loading stress level. The finding was also mentioned by Martin Leitner that due to HFMI/PIT reduced the notch at the weld toe of the butt joint, the fatigue initiation will be shifted to another location such as base metal[9]

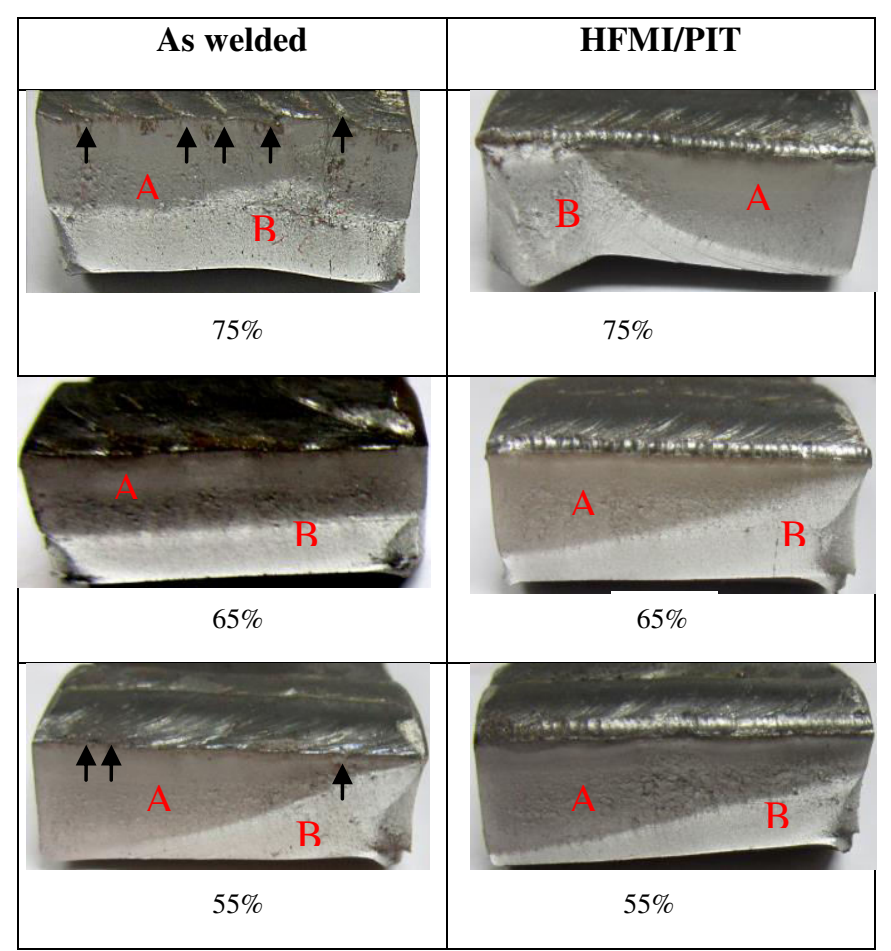

Fig. 11. Fracture surface fatigue test sample

\section{Conclusion}

In this study, the effects of HFMI/PIT on the butt weld of HSLA S460G2+M have been investigated by mean of fatigue life investigation, tensile test, hardness test and fracture surface examination. From the investigation of the experiments results, some conclusions arises as follows:

i. The HFMI/PIT treatment influenced the tensile strength of the welded specimens. The HFMI/PIT is modified the geometry and caused plastic deformation on the treated area, eliminate the surface defects of weld metal and weld toe.

ii. The hardness value apparently increased at base metal and heat affected zone (HAZ) area. The hardness increment is due to the HFMI/PIT modified the local geometry and deformed the plastically material by work hardening.

iii. The HFMI/PIT treatment on the weld toe of the butt joint of S460G2+M show benefit fatigue strength factor of 1.3 is achieved. The FAT Induction of compressive residual stress at the treated area and modifying the notch geometry at the weld toe results to fatigue cycle increased for HFMI/PIT treated specimen. 
iv. The FAT class of the as-welded and HFMI/PIT specimens exceeded the FAT class of IIW recommendation [15].

v. The fracture surface of the fatigue specimen for the as welded and HFMI/PIT types not show much different, except the existing multiple crack initiation which known as ratchet marks findings at the untreated due to non smooth weld toe geometry.

vi. The investigation shows an increment of Fatigues strength eventhough the welding process was conducted by unprofessional welder in this case engineer student.

As recommendation, the quality of welding process, HFMI/PIT treated procedure and fatigue test should be further investigated in order to reduce the resources such as material, power energy, consumable and achieved a good novelty research this can be done by using FEM simulation.

The authors would like to express their gratitude to aerospace laboratory technician Mr. Muhammad Sharizal for his guidance and support during the fatigue test execution. Special thanks also to University Kuala Lumpur Malaysia France Institute (UNIKLMFI), Nusantara Technologies Sdn. Bhd and Technogerma Engineering \& Consulting, ERASMUS+ and ASEA UNINET for the technical contribution. This research is financially sponsored by Fundamental Research Grant Scheme (FRGS) with Reference Nr: FRGS/1/2016/TK03/UITM/03/2.

\section{References}

1. B. Eccles, "Fatigue Failure Of Welded Joints", p.40.https://canteach.candu.org/Content\%20Libr ary/20053437.pdf

2. S. Ragu Nathan, V. Balasubramanian, S. Malarvizhi, and A. G. Rao, "Effect of welding processes on mechanical and microstructural characteristics of high strength low alloy naval grade steel joints", Def. Technol., vol. 11, no. 3, pp. 308-317, (2015).

3. F. B. Pickering, "High Strength Low Alloy Steels", Mater. Sci. Technol., vol. 45, no. 4, pp. 295-301, (2006).

4. "Standard - BS EN 10225 Weldable structural steels for fixed offshore structures Technical delivery conditions.pdf."(2001) .

5. "Current world-wide trends in the usage of modern steel plates for bridge constructions.pdf"

6. J. Johnson, "Fatigue Improvement Techniques for Welds".

7. G. B. Marquis, E. Mikkola, H. C. Yildirim, and Z. Barsoum, "Fatigue strength improvement of steel structures by high-frequency mechanical impact: Proposed fatigue assessment guidelines", Weld. World, vol. 57, no. 6, pp. 803-822, (2013).

8. G. Marquis and Z. Barsoum, "Fatigue strength improvement of steel structures by highfrequency mechanical impact: Proposed procedures and quality assurance guidelines", Weld. World, vol. 58, no. 1, pp. 19-28, (2014).

9. M. Leitner, M. Stoschka, R. Schanner, and W. Eichlseder, "Influence of high frequency peening on fatigue of high-strength steels", FME Trans., vol. 40, no. 3, pp. 99-104, (2012).

10. M. Leitner, M. Stoschka, and W. Eichlseder, "Contribution to the fatigue enhancement of thin-walled, high-strength steel joints by high frequency mechanical impact treatment", pp. 115.

11. M. Leitner, Z. Barsoum, and F. Schäfers, "Crack propagation analysis and rehabilitation by HFMI of pre-fatigued welded structures", Weld. World, vol. 60, no. 3, pp. 581-592, (2016).

12. P. Gerster, F. Schäfers, and M. Leitner, "Pneumatic Impact Treatment (PIT) Application and Quality Assurance", Int. Inst. Weld., pp. 1-11, (2013).

13. M. H. and S. J. M. H-P Lieurade, "Recommendation on The Fatigue Testing of Welded Components", Int. Inst. Weld., no. XIII2140-06, pp. 1-25, (2012).

14. S. Practice, "Standard Practice for Statistical Analysis of Linear or Linearized Stress-Life ( SN ) and Strain-Life ( e -N ) Fatigue Data 1", vol. 91, no. Reapproved, pp. 1-7, (1998).

15. A. Hobbacher, "Recommendations for Fatigue Design of Welded Joints and Components", IIW Doc. IIW-1823-07 ex XIII-2151r4-07/XV1254r4-07, pp. 1-149, (2008).

16. A. Harati Ebrahim and A. för tillverkningsprocesser O. Högskolan Väst Institutionen för ingenjörsvetenskap, Fatigue strength of welds in $800 \mathrm{MPa}$ yield strength steels: Effects of weld toe geometry and residual stress., no. 3. (2015).

17. N. W. Sachs, "Understanding the surface features of fatigue fractures: How they describe the failure cause and the failure history", J. Fail. Anal. Prev., vol. 5, no. 2, pp. 11-15, (2005). 